\title{
Relación entre morfología foliar de antófitos y factores abióticos en las principales pluvisilvas de la Región Oriental cubana
}

\author{
Eddy Martínez Quesada \\ Centro de Investigaciones de Ambiente de Camagüey. Cisneros 105 altos, e/ Pobre y Ángel. Camagüey 1, C.P. 70100. \\ Cuba; eddy@cimac.cu
}

Recibido 22-IV-2008. Corregido 21-IX-2008. Aceptado 23-X-2008.

\begin{abstract}
Relationship between antophyte foliar morphology and abiotic factors in the main rainforests of Eastern Cuba. The foliar morphology of representative antophytes in four rainforest types of Eastern Cuba was studied in relation to the main abiotic factors. Although there are several leaf types in these forests, the microphyll type is the most important among endemic species in the ophiolites complex and the Montane rainforest. At the Lowland rainforest (metamorphic complex) the mesophyll leaf was the most important. Most foliar epidermis had structures normally found in mesomorphic plants, but xeromorphic and higromorphic morphologies were also present. Rev. Biol. Trop. 57 (1-2): 235-256. Epub 2009 June 30.
\end{abstract}

Key words: foliar morphology, epidermis, rainforests, ecology, Cuban Oriental Region.

Las pluvisilvas de la Región Oriental cubana se hallan influenciadas por determinados factores ecológicos que determinan su estructura, funcionamiento y composición florística (Fornaris et al. 2000, Reyes et al. 2005, Reyes y Acosta 2005 a y b, Viña 2005, Martínez 2006). Entre esos se encuentran el sustrato, la iluminación y el clima (régimen de precipitaciones, temperatura, humedad relativa, nieblas, etc.). Otros como la exposición, el grado de la pendiente y la pedregosidad también pueden ejercer su influencia. Todos o algunos de ellos actúan de forma interrelacionada en el ecosistema y repercuten en la fisonomía del bosque.

Borhidi y Muñiz (1980), Borhidi (1991), Reyes y Acosta (2005 a) y Reyes (2006) al mencionar las características de las pluvisilvas cubanas se refirieron a los rasgos morfológicos de estos bosques, basados en el tamaño de las hojas. Por otra parte, Borhidi (1995) indicó que muchas de las familias presentes en la flora de Cuba, provenientes del Centro Amazónico de Gondwana están representadas por géneros y especies micrófilos y xeromorfos, muchos de ellos en forma de lianas y arbustos esclerófilos y espinosos o con una de esas dos últimas características. También León et al. (2005) estudiaron la morfología y los hábitos de vida de la flora endémica distrital de la Sierra de Nipe, aunque ésta se encuentra asociada a otras formaciones vegetales.

En Cuba no se tienen antecedentes respecto a los estudios de epidermis foliar en las pluvisilvas; no obstante, se conoce de la existencia de las contribuciones de Gutiérrez (1991), Díaz y Rankin (1998) y Ventosa (2004), quienes analizaron las modificaciones anatómicas de algunas especies en relación con el hábitat, pero en otros ecosistemas.

El objetivo del trabajo es estudiar la morfología foliar, basado en el tamaño y el ápice de las hojas, así como también los caracteres epidérmicos de las especies que son representativas de las principales pluvisilvas de la Región Oriental de Cuba, para establecer una relación entre las características morfológicas 
y los principales factores abióticos que inciden en su desarrollo.

\section{MATERIALES Y MÉTODOS}

Área de estudio: Este estudio se llevó a cabo en la Región Oriental de Cuba, mediante expediciones de campo a localidades ubicadas en las áreas ocupadas por las pluvisilvas, donde se efectuaron inventarios florísticos y se recolectaron especímenes entre los años 1997-2004. La Región Oriental de Cuba se define como la unidad natural-antrópica que se extiende por el extremo Este de Cuba, al Sur de una línea imaginaria que va desde el centro del Golfo de Guacanayabo hasta el borde Norte de la
Bahía de Banes. Limita al Norte con la Región Central (en su mayor parte con las Subregiones Llanura de Camagüey y Grupo Orográfico de Maniabón), al Noreste con el Océano Atlántico, al Este con el Paso de los Vientos, al Sur con el Mar Caribe y al Oeste con el mencionado Golfo de Guacanayabo (Núñez 1954, Cañas 1978, Mateo \& Acevedo 1989, Núñez \& Viña 1989). Esta región consta de 11 subregiones como parte del país emergido (Núñez \& Viña, 1989), dos de las cuales (Grupo Orográfico de Sagua-Baracoa y Sierra Maestra) contienen las pluvisilvas (Fig. 1). Las localidades visitadas para los inventarios y colectas en los tipos de pluvisilvas son las que se exponen a continuación:

\begin{tabular}{|c|c|c|}
\hline Subregión & Tipo de pluvisilva & Localidades \\
\hline \multirow[t]{3}{*}{ Grupo Orográfico de Sagua-Baracoa } & $\begin{array}{l}\text { Pluvisilva de baja altitud sobre } \\
\text { complejo metamórfico }\end{array}$ & $\begin{array}{l}\text { Arroyo Bueno } \\
\text { Cocalito }\end{array}$ \\
\hline & $\begin{array}{l}\text { Pluvisilva de baja altitud y } \\
\text { submontana sobre ofiolitas }\end{array}$ & $\begin{array}{l}\text { Mina Mercedita } \\
\text { Piedra La Vela } \\
\text { Pinares de Mayarí } \\
\text { Sierra La Boca } \\
\text { Batista } \\
\text { La Zanja } \\
\text { Nuevo Mundo }\end{array}$ \\
\hline & $\begin{array}{l}\text { Pluvisilva submontana sobre suelos } \\
\text { de mal drenaje }\end{array}$ & $\begin{array}{l}\text { Altiplanicie de Monte Iberia } \\
\text { Altiplanicie El Toldo }\end{array}$ \\
\hline \multirow[t]{10}{*}{ Sierra Maestra } & Pluvisilva montana & Subida hacia la cima del Pico Mogote \\
\hline & & Cima del Pico Mogote \\
\hline & & El Olimpo \\
\hline & & La Gran Piedra (alrededores del motel) \\
\hline & & La Isabelica, Gran Piedra \\
\hline & & Loma del Gato \\
\hline & & Alto de La Bayamesa \\
\hline & & Pico La Botella \\
\hline & & Pico Martí \\
\hline & & El Zapato \\
\hline
\end{tabular}




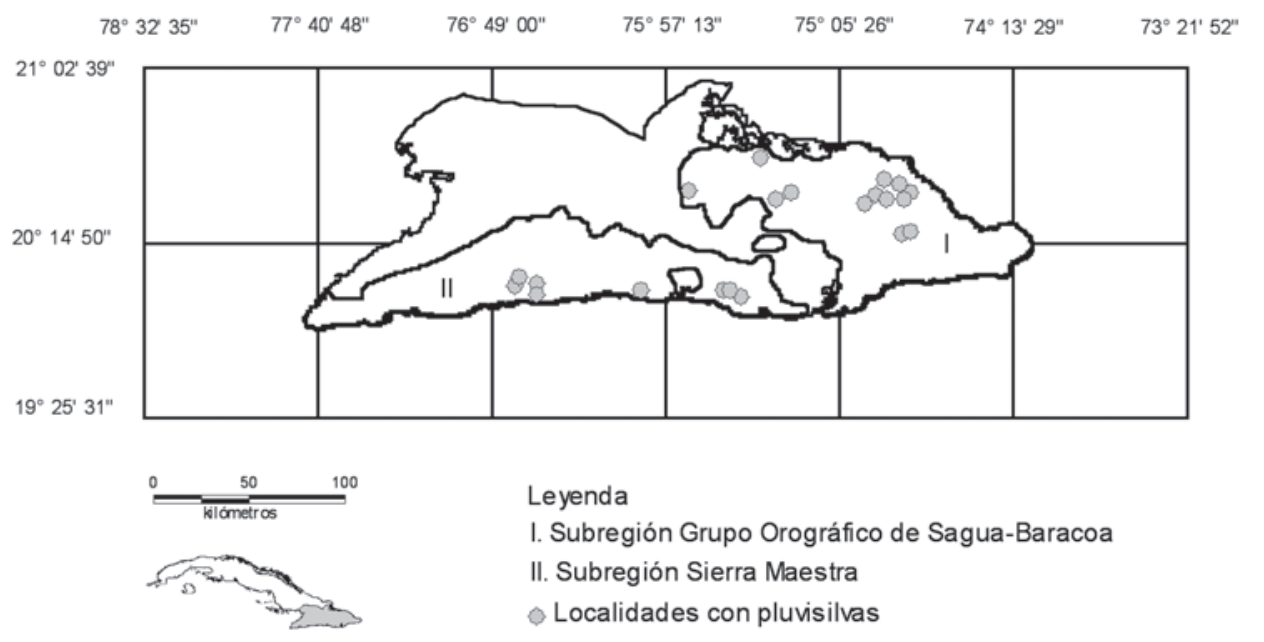

Fig. 1. Cuba oriental: subregiones y localidades de recolecta en áreas de pluvisilvas.

Selección de las hojas: Se utilizaron hojas maduras de ejemplares recolectados en los distintos tipos de pluvisilvas, que están depositados en los herbarios BSC, HAJB y HACC y en la selección se tuvo en cuenta la diversidad de hábitos de vida (principalmente árboles, arbustos, hierbas y lianas). En el caso de las especies dimórficas de Marcgravia se procesaron las hojas de las ramas fértiles.

Medición de las hojas y definición de los tipos de ápices: En el análisis del tamaño de las hojas se utilizaron cinco de ellas procedentes de ejemplares diferentes en 20 especies que pertenecen a la Pluvisilva de baja altitud y submontana sobre ofiolitas, 21 a la Pluvisilva submontana sobre suelos de mal drenaje, 20 de la Pluvisilva montana y 14 de la Pluvisilva de baja altitud sobre complejo metamórfico, para un total de 375 muestras. Cada hoja se colocó en un papel milimetrado para medir su longitud y ancho y se clasificó según el criterio de Borhidi (1976). El mismo tamaño de muestra se tuvo en cuenta para los tipos de ápices, los que se definieron a partir de la literatura consultada y de las observaciones realizadas. Debido a que algunas especies presentaron una combinación de tipos de hojas y más de un tipo de ápice, se decidió asumir el primero de ellos como el predominante cuando esto fue necesario para algún tipo de análisis.

Preparación de las tiras epidérmicas: Para el estudio de la epidermis foliar se tuvieron en cuenta las mismas muestras que se utilizaron en la medición del tamaño de las hojas. La epidermis se extrajo a partir de la parte media de todas las hojas, incluyendo los márgenes de éstas y se sometió a un proceso de maceración química en el cual se usó una mezcla de ácido nítrico y ácido acético concentrados o del primero de ellos con agua destilada, según la textura de la hoja, en proporción 1:1. Cuando el tejido epidérmico se separó del mesófilo, se procedió a recogerlo con la ayuda de agujas enmangadas. En algunos casos se necesitó utilizar una solución acuosa de hidróxido de sodio al $10 \%$ para eliminar de este tejido restos del mesófilo. Las tiras epidérmicas se sometieron a un proceso de tinción con una solución acuosa saturada de Safranina y se eliminó el exceso de colorante después de haberlas colocado en alcohol al 70\%. El montaje se llevó a cabo con gelatina glicerinada. 
Cortes transversales: En tres especies (Leucocroton pachyphyllus, Linodendron aronifolium y Votomita monantha) se realizaron cortes transversales manuales para observar estructuras epidérmicas notables en esta sección. Las porciones de la parte media de las hojas se sumergieron de forma previa en agua con glicerina en proporción 1:1. Por último se colocaron en una base de material sintético (polyestireno) y los cortes se efectuaron con hojas de afeitar de $0.1 \mathrm{~mm}$ de espesor.

Términos y conceptos empleados: $\mathrm{La}$ terminología que se utilizó para describir los dermotipos foliares fue la de Wilkinson (1979) y la de Barthlott (1981). Los términos lenticela y fisura se tomaron a partir de Roth (1990). Debido a que la epidermis es un tejido que no consta con espacios intercelulares (Esau 1977) es necesario definir los términos fisura y lenticela, que serán utilizados en este trabajo. Según Roth (1990) ambas estructuras se pueden definir como "agujeros epidérmicos que se originan de forma lisígena o esquizógena en las hojas de las plantas, cuya función está íntimamente relacionada con el intercambio gaseoso en aquellos hábitats donde existe una alta humedad atmosférica". En este caso el autor de este trabajo considera que la lenticela foliar es una estructura análoga a aquella de los tejidos secundarios de tallos y raíces por tener la misma función, pero un origen distinto.

Equipos utilizados: Las observaciones se realizaron con un microscopio óptico marca Carl Zeiss y un aumento de $400 \mathrm{x}$ como máximo. También se tomaron fotografías con la ayuda de una cámara digital de marca FD Mavica.

Clasificación de las pluvisilvas: La clasificación de las pluvisilvas se realizó de acuerdo con el criterio de Reyes y Acosta (2005 a), quienes consideran cuatro tipos de pluvisilvas en el Parque Nacional Alejandro de Humboldt, las que pueden encontrarse en toda la Subregión Grupo Orográfico de Sagua-Baracoa (Pluvisilva de baja altitud sobre complejo metamórfico,
Pluvisilva submontana sobre complejo metamórfico, Pluvisilva de baja altitud y submontana sobre ofiolitas y Pluvisilva submontana sobre suelos de mal drenaje); mientras que en la Subregión Sierra Maestra se utilizó la clasificación de Reyes (2006), el que reconoce sólo un tipo (Pluvisilva montana). En este estudio no se tuvo en cuenta la Pluvisilva submontana sobre complejo metamórfico.

\section{RESULTADOS}

Tamaño y ápice de las hojas: En general predominó la hoja micrófila (56\%), sobre todo en los endemismos. Por otra parte, aquellas macrófilas y mesófilas no se encontraron en las especies endémicas, (Cuadro 1).

Del análisis por tipos de pluvisilvas se obtuvo que en la Pluvisilva de baja altitud y submontana sobre ofiolitas y en la Pluvisilva submontana sobre suelos de mal drenaje la mayoría de las hojas son micrófilas; mientras que en la Pluvisilva de baja altitud sobre complejo metamórfico, mesófilas. Por otra parte, en la Pluvisilva montana fueron las hojas micrófilas y notófilas. Aquellas macrófilas y leptófilas se observaron rara vez entre todas las muestras analizadas (Cuadro 2). En las Figuras 2 y 3 se pueden apreciar algunos tipos de hojas, que corresponden a dos de las pluvisilvas estudiadas.

El ápice de las hojas varió de una especie a otra. Se reconocieron entre tres y seis tipos diferentes, en dependencia de los bosques estudiados. En la Pluvisilva de baja altitud y submontana sobre ofiolitas y en la Pluvisilva submontana sobre suelos de mal drenaje abundaron las hojas de ápice redondeado. Pocas especies se observaron con el ápice acuminado (11\%) y Cameraria latifolia (Apocynaceae) es la única que lo posee alargado y estrecho (Fig. 2).

Por otra parte, en la Pluvisilva de baja altitud sobre complejo metamórfico y en la Pluvisilva montana predominaron las hojas con ápices agudo y acuminado. En este sentido las hojas de Marcgravia rectiflora (Marcgraviaceae), Trophis racemosa, Pseudolmedia spuria (Moraceae) e 
CUADRO 1

Relación entre los tipos de hojas y las especies endémicas y no endémicas

TABLE 1

Relationship between leaf type and the endemic and non-endemic species

\begin{tabular}{|c|c|c|c|c|c|c|}
\hline \multirow{2}{*}{ Tipo de hoja } & \multicolumn{2}{|c|}{ Endemismos } & \multicolumn{2}{|c|}{ No endemismos } & \multicolumn{2}{|c|}{ Total } \\
\hline & No. especies & Porcentaje $^{1}$ & No. especies & Porcentaje $^{2}$ & No. especies & Porcentaje $^{3}$ \\
\hline Macrófila & - & - & 1 & 4 & 1 & 1 \\
\hline Mesófila & - & - & 7 & 26 & 7 & 9 \\
\hline Notófila & 6 & 13 & 6 & 22 & 12 & 16 \\
\hline Micrófila & 31 & 63 & 10 & 37 & 41 & 56 \\
\hline Nanófila & 10 & 20 & 2 & 7 & 12 & 16 \\
\hline Leptófila & 2 & 4 & - & - & 2 & 3 \\
\hline
\end{tabular}

Los supraíndices 1, 2 y 3 indican el total de endemismos, de no endemismos y de taxones infragenéricos respectivamente, que aparecen en los Cuadros 4-7.

\section{CUADRO 2}

Tipos de hojas encontrados en las pluvisilvas estudiadas

TABLE 2

Leaf types found in the studied rain forest

\begin{tabular}{lcccc}
\multirow{2}{*}{ Tipo de hoja } & \multicolumn{4}{c}{ Pluvisilvas } \\
Macrófila & 1 & 2 & 3 & 4 \\
Mesófila & - & - & 1 & - \\
Notófila & 1 & - & 5 & 1 \\
Micrófila & 1 & 1 & 3 & 7 \\
Nanófila & 17 & 13 & 3 & 10 \\
Leptófila & - & 7 & 2 & 2 \\
& & 2 & - & -
\end{tabular}

$1=$ Pluvisilva de baja altitud y submontana sobre ofiolitas, 2=Pluvisilva submontana sobre suelos de mal drenaje, 3=Pluvisilva de baja altitud sobre complejo metamórfico, 4=Pluvisilva montana.

Hirtella triandra (Chrysobalanaceae) pueden funcionar como goteros, por tener el ápice acuminado en mayor o menor medida en el primer bosque; mientras que en el segundo serían Lisianthius glandulosus (Gentianaceae), Lobelia asurgens (Lobeliaceae) y Miconia mirabilis (Melastomataceae), (Cuadro $3 \mathrm{y}$ Fig. 3).

\section{Estructuras epidérmico-foliares}

Patrones de las paredes de las células epidérmicas ordinarias: Los patrones de las paredes anticlinales y periclinales de las células epidérmicas ordinarias intercostales variaron entre las especies estudiadas, incluso dentro

\section{CUADRO 3}

Tipos de ápices observados en las pluvisilvas estudiadas. Los valores están expresados en porcentaje

TABLE 3

Apex types in the studied rain forests. The values are expressed in percentage

\begin{tabular}{lcccc} 
Tipo de ápice & \multicolumn{5}{c}{ Tipos de pluvisilvas } \\
& 1 & 2 & 3 & 4 \\
acuminado & 11.1 & 8.6 & 57 & 35 \\
apiculado & - & - & - & 10 \\
agudo & 11.1 & 13 & 35 & 35 \\
cuspidado & - & - & - & 5 \\
obtuso & 27.7 & 26 & - & 10 \\
redondeado & 50 & 47.8 & 7.1 & 10
\end{tabular}

$1=$ Pluvisilva de baja altitud y submontana sobre ofiolitas, 2=Pluvisilva submontana sobre suelos de mal drenaje, 3=Pluvisilva de baja altitud sobre complejo metamórfico, 4=Pluvisilva montana. 


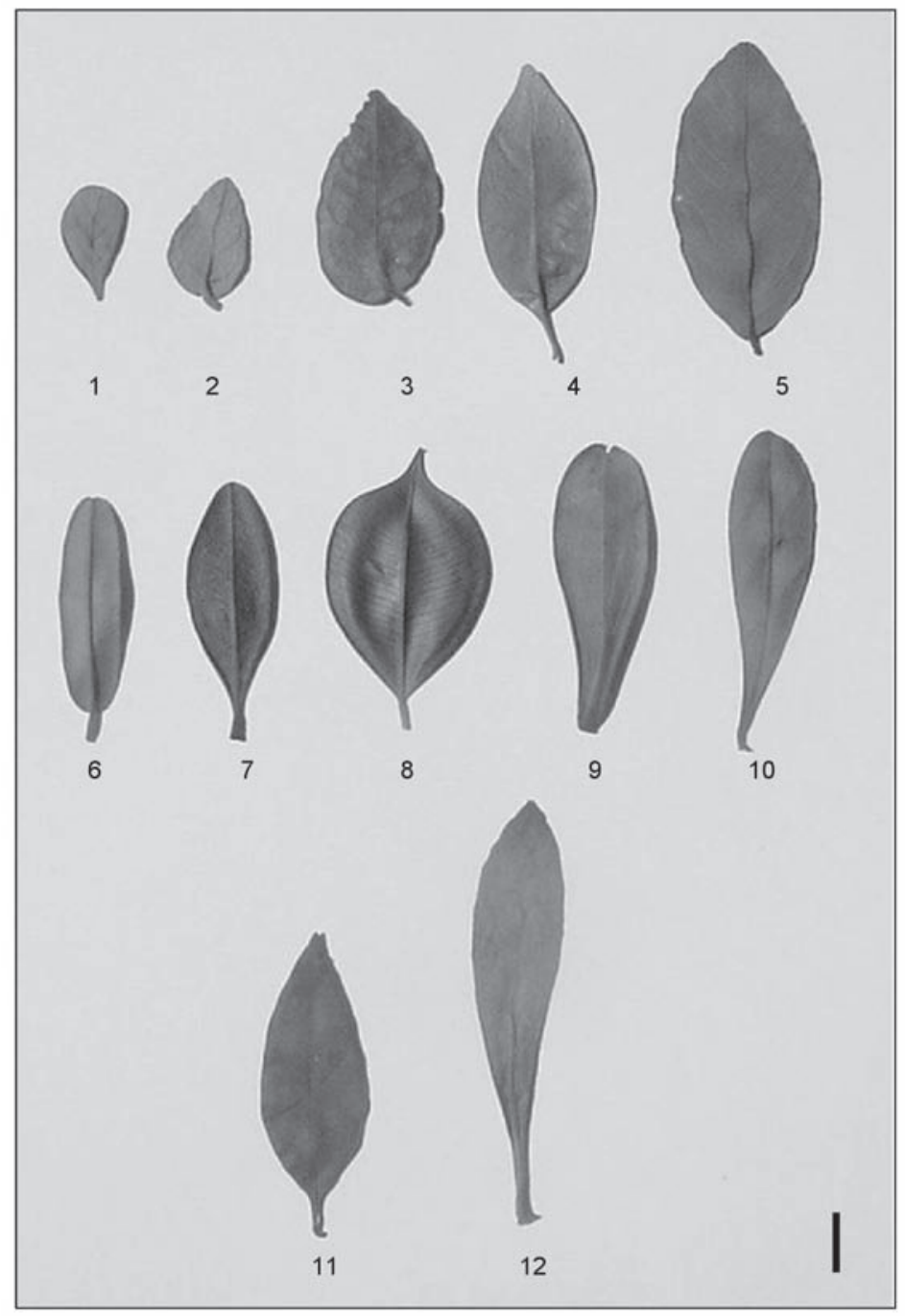

Fig. 2. Algunos tipos de hojas analizados en la Pluvisilva de baja altitud y submontana sobre ofiolitas. 1. Jacaranda arborea, 2. Grisebachianthus lantanifolius, 3. Chaetocarpus acutifolius, 4. Chiococca cubensis, 5. Linodendron aronifolium, 6. Manilkara jaimiqui ssp. jaimiqui, 7. Cyrilla nipensis, 8. Cameraria latifolia, 9. Purdiaea stenopetala var. stenopetala, 10. Laplacea moaensis, 11. Byrsonima spicata, 12. Scaevola wrightii. La barra equivale a $1 \mathrm{~cm}$.

de una misma especie. En la Pluvisilva de baja altitud y submontana sobre ofiolitas y en la Pluvisilva submontana sobre suelos de mal drenaje la mayoría de las especies tuvieron las paredes rectas y curvadas adaxialmente, pero en la superficie abaxial se apreciaron mayormente onduladas (Cuadros 4 y 5; Fig. 4 A-C). Se encontraron estrías en la superficie abaxial de Byrsonima spicata, aunque no en todas las células (Fig. 4 D) y Jacaranda arborea y en la superficie adaxial de Ouratea revoluta, Symphysia alainii y Scolosanthus wrightianus, la abaxial de Votomita monantha y en ambas superficies de Schradera cephalophora.

En la Pluvisilva de baja altitud sobre complejo metamórfico se observó un predominio de paredes rectas y curvadas en la superficie adaxial, mientras que en la abaxial la mitad de 


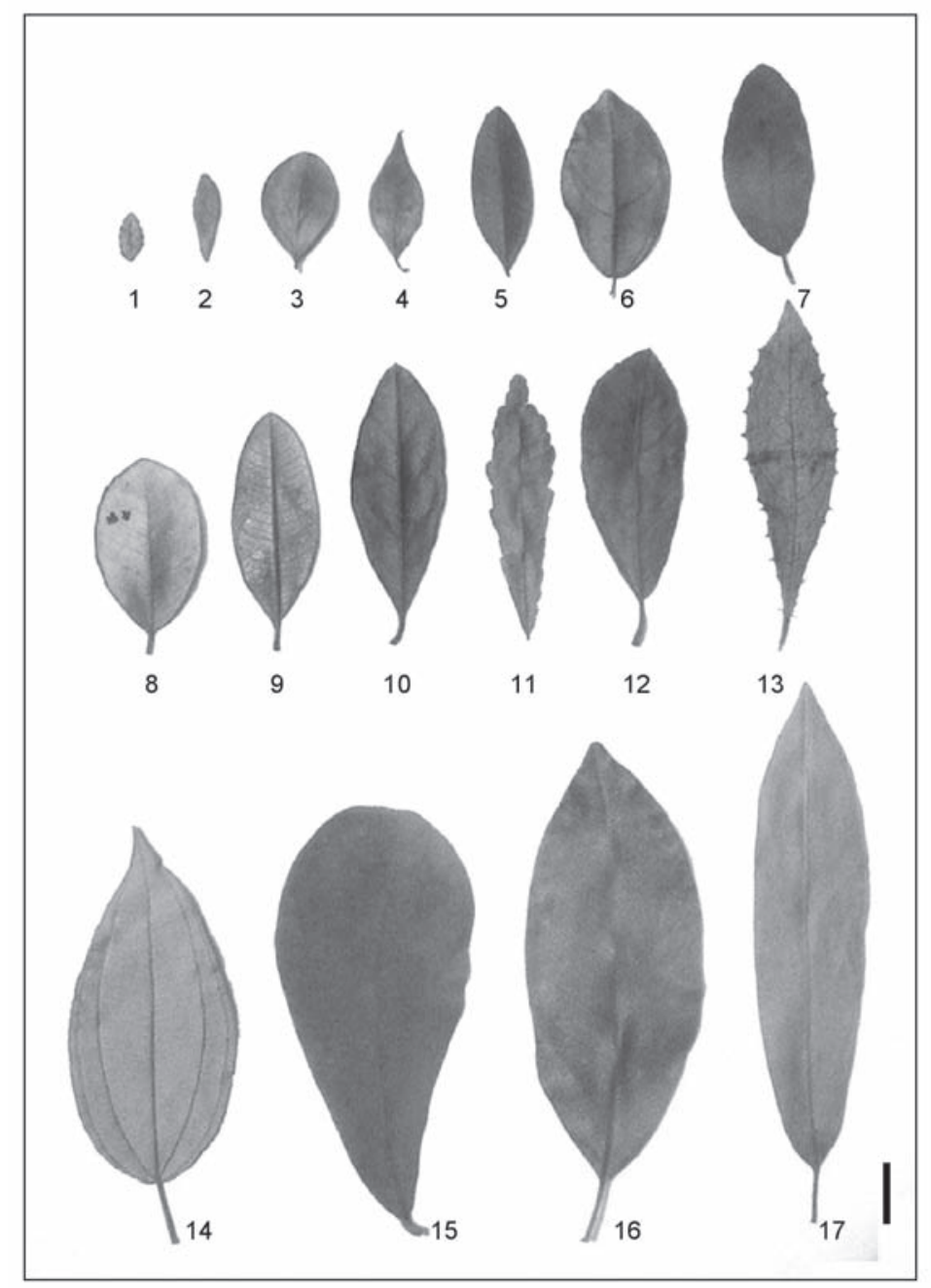

Fig. 3. Algunos tipos de hojas analizados en la Pluvisilva montana. Some leaf types analyzed on Montane rain forest. 1. Weinmannia pinnata. 2. Myrica punctata, 3. Vaccinium leonis, 4. Lisianthius glandulosus, 5. Matayba domingensis, 6. Lunania subcoriacea, 7. Ageratina paucibracteata, 8. Elaeodendron lippoldii, 9. Guatteria blainii, 10. Lasianthus lanceolatus, 11. Myrica shaferi, 12. Clethra cubensis, 13. Lobelia assurgens var. assurgens, 14. Miconia mirabilis, 15. Ocotea cuneata, 16. Magnolia cubensis ssp. cubensis, 17. Myrsine coriacea. La barra equivale a $1 \mathrm{~cm}$.

las especies analizadas lo presentaron (Cuadro 6 y Fig. 5 A-C, J, K). Las esculturaciones secundarias correspondieron a estriaciones cuticulares en la superficie adaxial de Miconia prasina y Cupania americana, en la abaxial de Guarea guidonia y en ambas superficies de Notopleura guadalupensis y Zanthoxylum martinicense (Fig. 5 A, B, F).
En la Pluvisilva montana predominó el patrón ondulado en ambas superficies (Cuadro 7 y Fig. 5 D) y se observaron estrías en las paredes de la superficie adaxial de Lisianthius glandulosus y Lobelia asurgens var. asurgens y Magnolia cubensis ssp. cubensis y en la abaxial de Matayba domingensis (Fig. 5 G). Se detectaron paredes gruesas en la superficie adaxial 


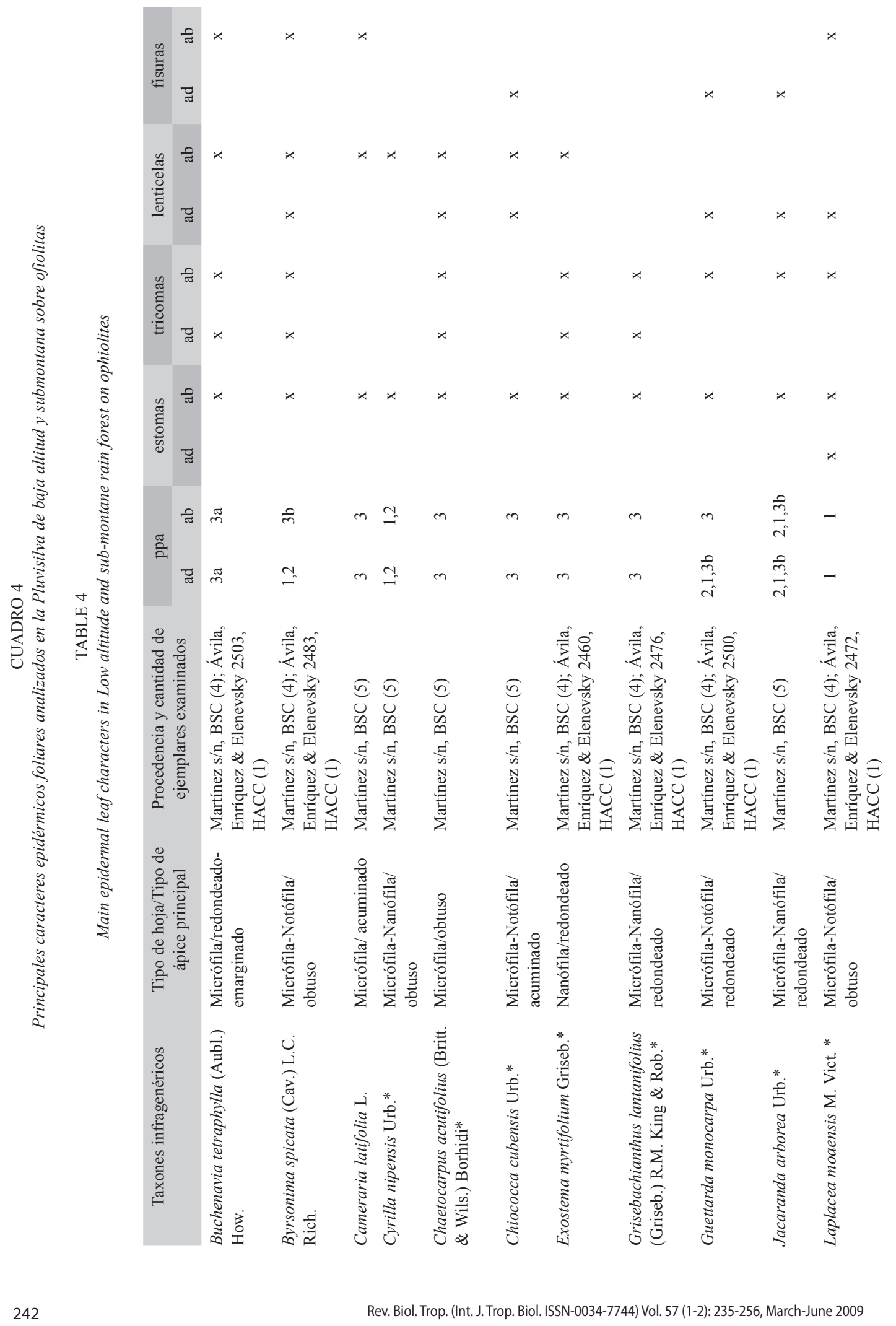




$$
\mid
$$




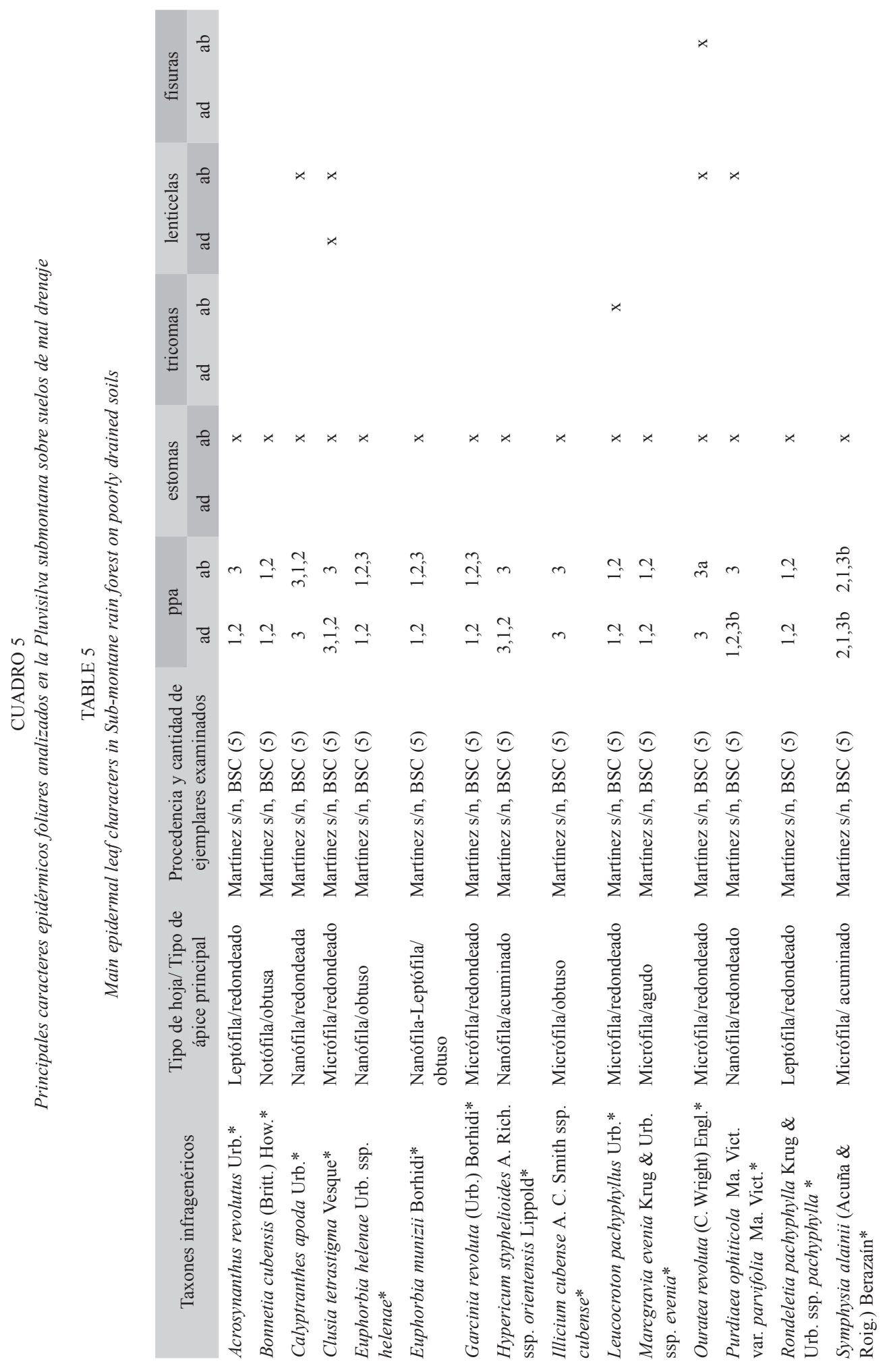




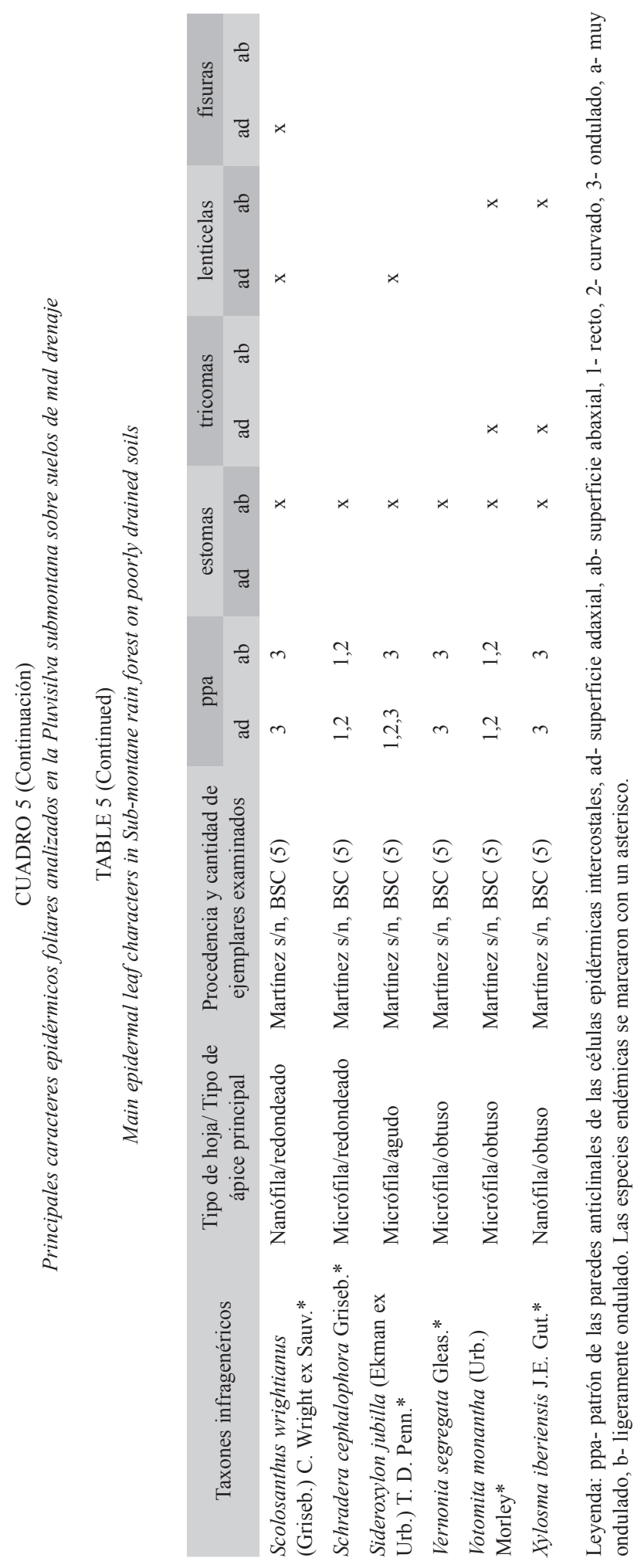



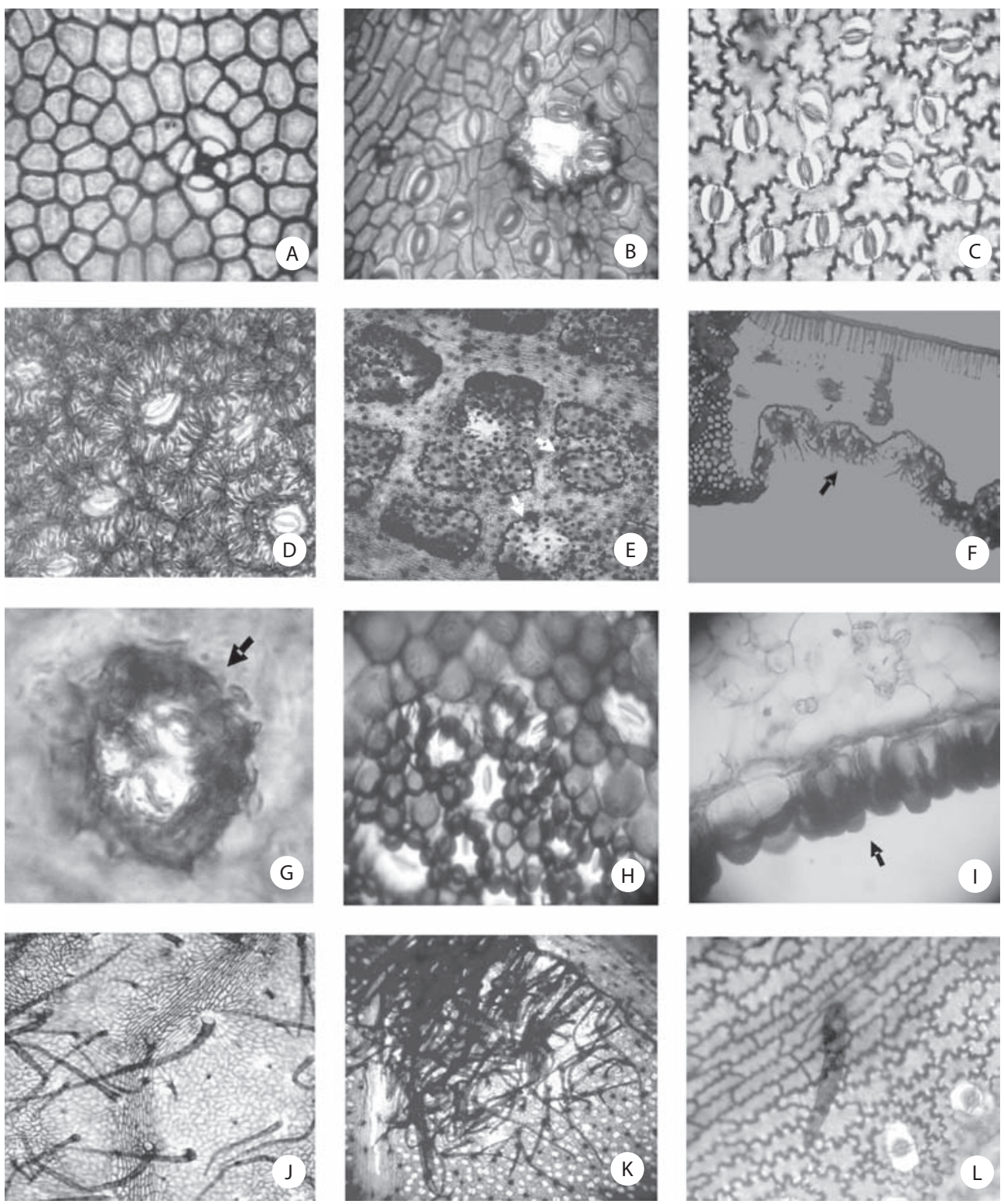

Fig. 4. Sección paradermal y transversal de algunas especies estudiadas en las pluvisilvas. Paradermal and transversal section of some studied species on rain forests. Pluvisilva de baja altitud y submontana sobre ofiolitas: A-D, H-K; Pluvisilva submontana sobre suelos de mal drenaje: E, F, G y L. A y B. superficie adaxial y abaxial respectivamente de Byrsonima spicata. En B se observa la formación de una lenticela, C. superficie abaxial de Chaetocarpus acutifolius, D. superficie abaxial de Jacaranda arborea, E. superficie abaxial de Leucocroton pachyphyllus, las flechas indican las áreas deprimidas donde se encuentran los estomas, F. sección transversal de la especie anterior a través de una cripta estomática, G. superficie abaxial de Votomita monantha, donde se observan los estomas agrupados, H. superficie abaxial de Linodendron aronifolium, I. sección transversal de la misma especie mostrando las papilas, J. superficie abaxial de Chaetocarpus acutifolius, K. superficie abaxial de Exostema myrtifolium con tricomas en la axila de las venas, L. superficie abaxial de Ravenia shaferi var. ekmanii. A-C, D x 400; G, H-J, L x 100; E, F, K x 50. 


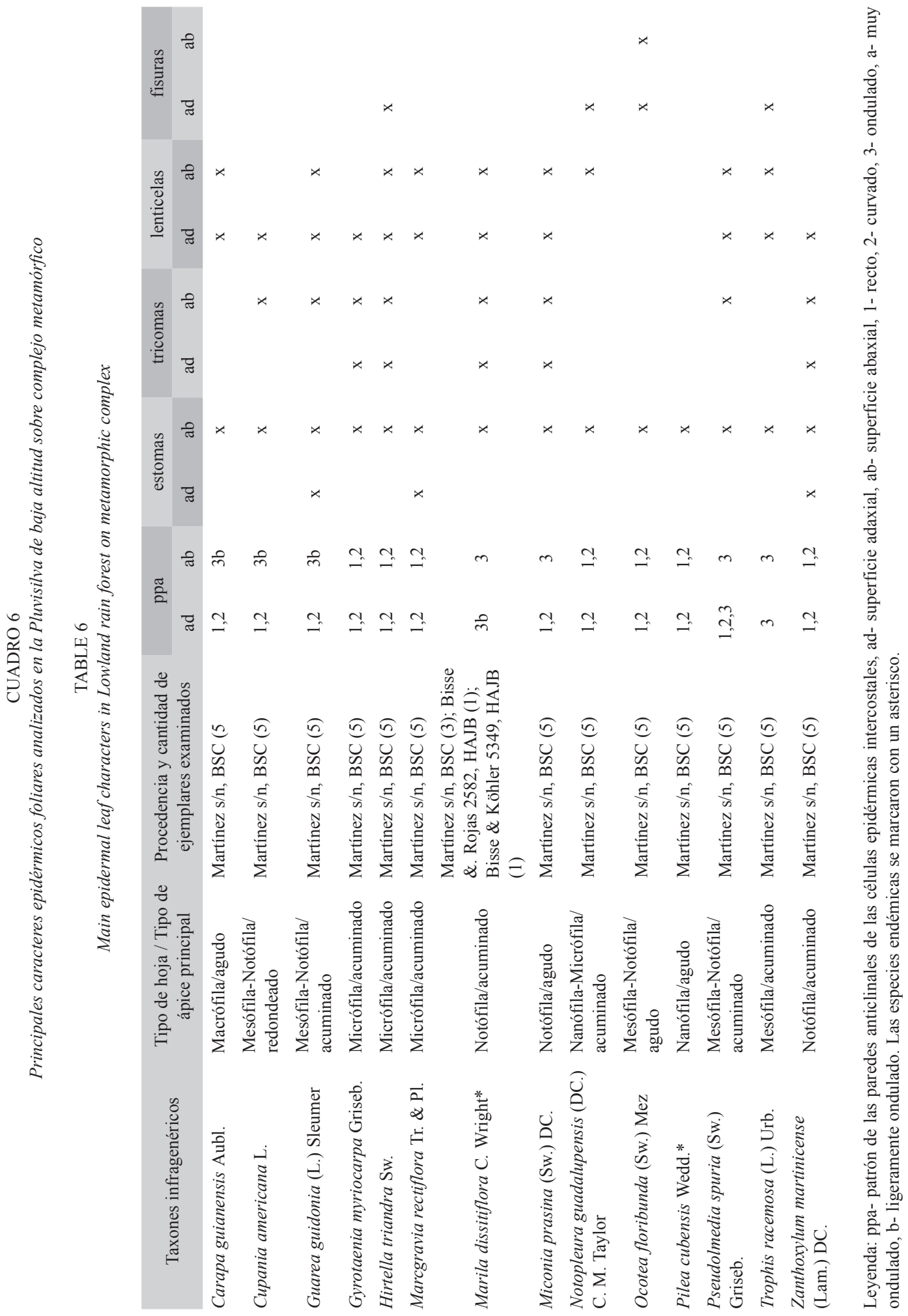



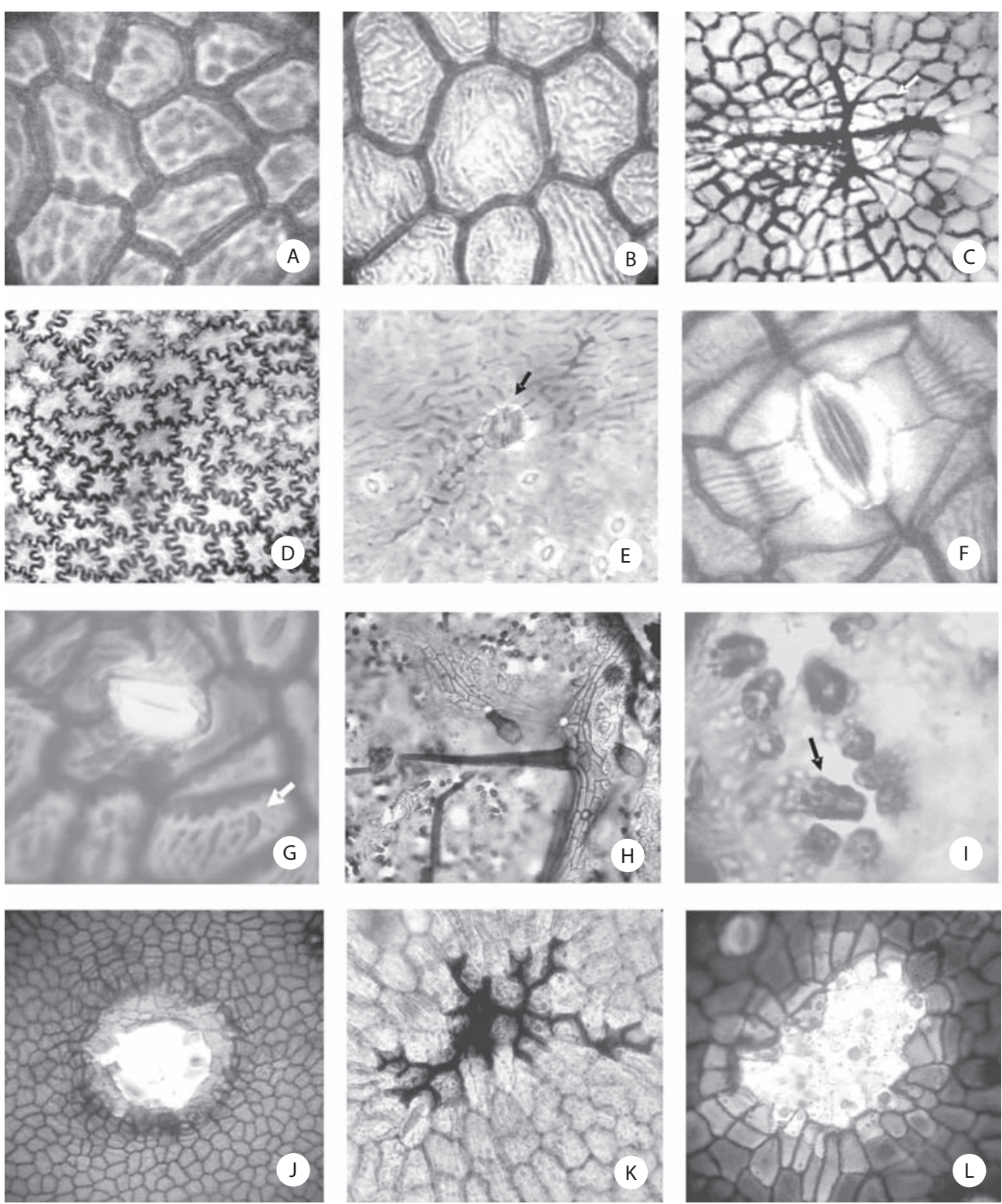

Fig. 5. Secciones paradermales de algunas especies estudiadas en las pluvisilvas. Pluvisilva de baja altitud sobre complejo metamórfico: A-C, E, F, H-L; Pluvisilva montana: D y G. A. superficie adaxial de Cupania americana B. superficie adaxial de Miconia prasina, C. fisura en la superficie adaxial de Trophis racemosa, D. superficie adaxial de Vaccinium leonis, E. estoma gigante en la superficie abaxial de Trophis racemosa, F. superficie abaxial de Guarea guidonia, G. superficie abaxial de Matayba domingensis donde se observan las estrías cuticulares, H \& I. tricomas y papilas en la superficie abaxial de Cupania americana, en I una ampliación de las papilas, J. lenticela en la superficie adaxial de Miconia prasina, K. fisura en la superficie adaxial de Licianthius glandulosus, L. lenticela en la superficie abaxial de Exostema myrtifolium. A, B, E, F, G, H-J x 400; C, D, K, L x 100. 


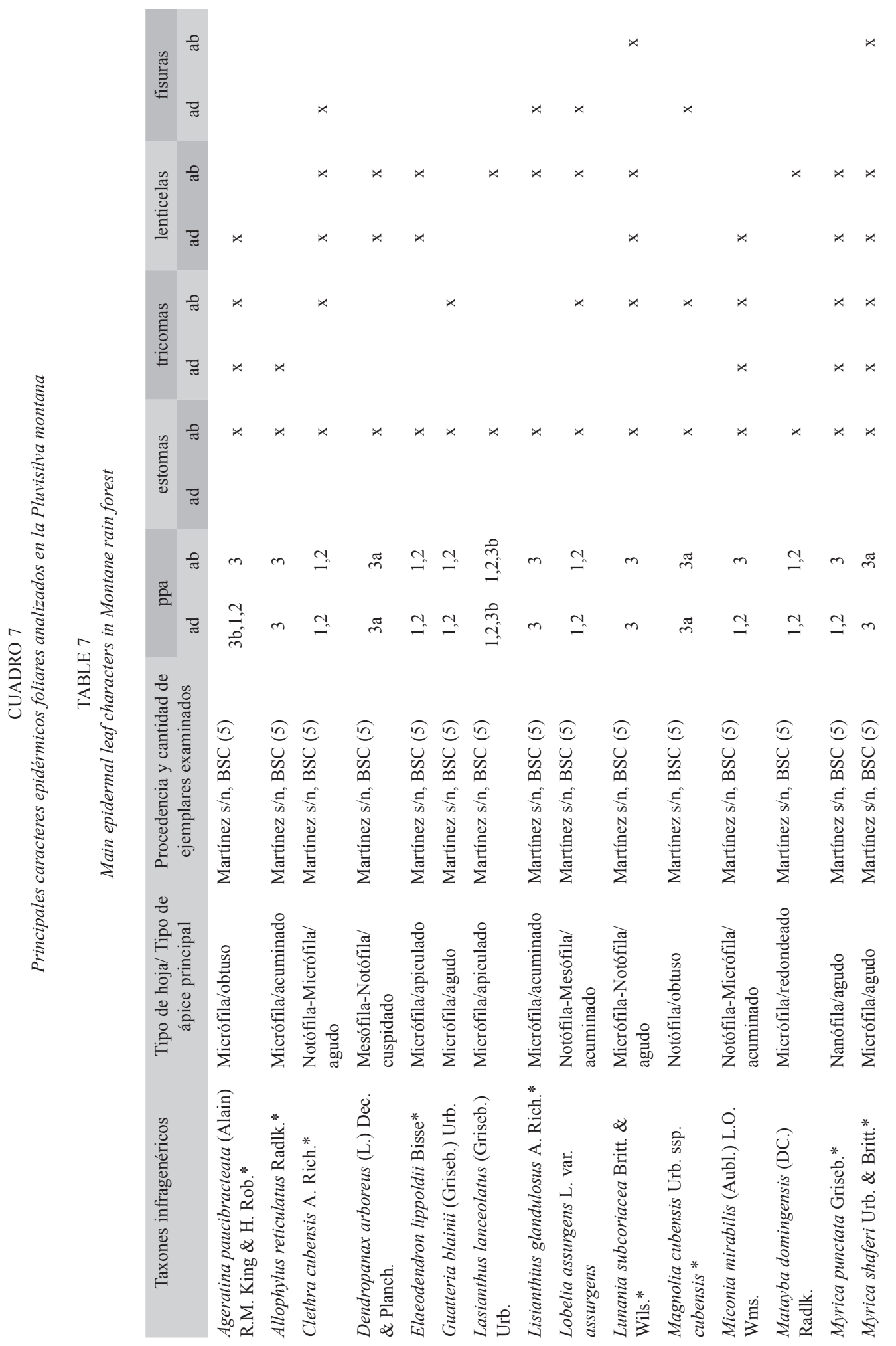




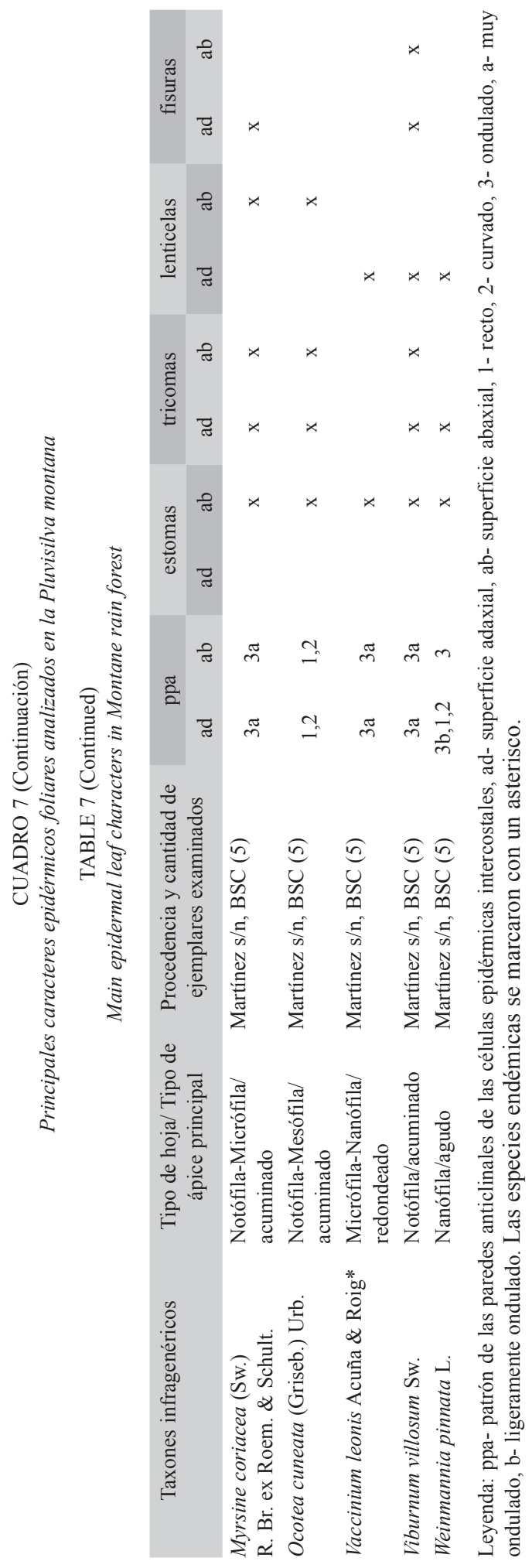

de Elaeodendron lippoldii, Myrica punctata, Byrsonima spicata, (Fig. 4 A), Illicium cubense, Ouratea revoluta y en Calypthrantes apoda.

La mayor parte de las esculturaciones secundarias en las células epidérmicas ordinarias correspondieron a estrías, pero en Cupania americana se observaron reticuladas (Fig. 5. A) y en Scolosanthus wrightianus tuvieron forma de micropapilas (verrucosas).

Estomas: En la mayoría de las especies estudiadas se observaron los estomas restringidos a la superficie abaxial (hoja hipostomática) y sólo en Scaevola wrightii se encontraron abundantes en ambas superficies (hoja anfistomática). También se hallaron adaxialmente en Purdiaea stenopetala var. stenopetala, aunque escasos; en Zanthoxylum martinicense y Marcgravia rectiflora, donde se detectaron entre las células epidérmicas ordinarias, y en Guarea guidonia, en el margen de la hoja (hoja hipoanfistomática), (Cuadros 4-7 y Fig. 4 B-E, G, H y 5 E-G).

Todos los estomas aparecieron al nivel de la epidermis menos en Leucocroton pachyphyllus, que están en áreas deprimidas de la epidermis (criptas) con numerosos tricomas estipitados que tapizan la cavidad (Fig. 4 E, F). Los de Votomita monantha se encontraron reunidos en pequeños grupos y toda la estructura está rodeada por un engrosamiento cuticular (Fig. 4 G). La sección transversal de la hoja mostró que éstos quedaban por debajo del nivel de la proyección de dicho engrosamiento. Por otra parte, en Manilkara jaimiqui ssp. jaimiqui la cutícula se observó muy engrosada en las células anexas de los estomas, e incluso cubre parte de las oclusivas. También se encontraron estrías en las mismas células de Laplacea moaensis y sólo en las anexas de los estomas de Magnolia cubensis ssp. cubensis, Vernonia hieracioides, Grisebachianthus lantanifolius y Zanthoxylum martinicense (en los estomas gigantes) y en las células oclusivas y anexas de Garcinia revoluta y Jacaranda arborea, en este último caso las células anexas se apreciaron festoneadas y las estrías cubrieron parte de las células oclusivas (Fig. 4 D). 
El 22\% de las especies analizadas presentaron estomas gigantes y se detectaron en todas las pluvisilvas. Las especies que los poseen son Carapa guianensis, Marila dissitiflora, Guarea guidonia, Ocotea floribunda, Zanthoxylon martinicense, Trophis racemosa (Fig. 5 E), Lunania subcoriacea, Matayba domingensis, Clethra cubensis, Elaeodendron lippoldii Lasianthus lanceolatus, Buchenavia tetraphylla, Jacaranda arborea, Exostema myrtifolium, Ocotea leucoxylon, Ouratea revoluta, Sideroxylon jubilla y Ravenia shaferi var. ekmanii. Se observaron sobre las venas o próximos a éstas en la mayor parte de los casos, excepto en Sideroxylon jubilla que los posee en las áreas intercostales.

Tricomas y papilas: Se encontraron tricomas vivos de diferentes tipos en el $46 \%$ de las especies y en la mayoría de los casos éstos no fueron abundantes, sobre las venas y en las áreas intercostales de ambas superficies o en una de ellas (Cuadros 4-7). En Lobelia asurgens var. asurgens, Zanthoxylum martinicense, Chaetocarpus acutifolius, Guettarda monocarpa y Exostema myrtifolium se apreciaron más abundantes sobre la vena media de la superficie abaxial y en Viburnum villosum, relativamente abundantes en las áreas intercostales de las dos superficies. En Exostema myrtifolium los tricomas se detectaron más numerosos en las axilas de los nervios, donde forman mechones (domacios). Sólo en Miconia mirabilis y Ocotea cuneata se observó una alta densidad de tricomas en esta superficie, de tal manera que los estomas quedaban ocultos por ellos. La mayor parte de las especies que presentaron esta estructura se encontraron en la Pluvisilva montana (18\%), la Pluvisilva de baja altitud y submontana sobre ofiolitas (13\%) y la Pluvisilva de baja altitud sobre complejo metamórfico (12\%); mientras que en la Pluvisilva submontana sobre suelos de mal drenaje los tricomas estuvieron ausentes en casi todas las especies estudiadas, (Cuadros 4-7 y Fig. 4 J, K, L).

Se observaron papilas sólo en la superficie abaxial de Linodendron aronifolium y Cupania americana. En el primer caso los estomas de las áreas intercostales estaban totalmente rodeados por dichas papilas, de manera que ellos quedaban por debajo de las mismas (Fig. $4 \mathrm{H}$, I y $5 \mathrm{H}, \mathrm{I})$.

Lenticelas y fisuras: En todos los bosques estudiados se detectaron lenticelas y fisuras (66\% y $28 \%$ respectivamente) y se distribuyen en una sola cara de la hoja o en ambas superficies según el tipo de pluvisilva (Cuadros 4-7, Fig. 4 B y 5 C, J, K, L). Se detectaron sobre las venas o próximas a éstas y también en las áreas intercostales. Las lenticelas abundaron particularmente en la superficie adaxial de Myrica shaferi y en la abaxial de Clusia tretrastigma. Estas tuvieron gran tamaño (ca. 1 $\mathrm{mm}$ ) en Pseudolmedia spuria, Ocotea cuneata y Purdiaea ophiticola var. parvifolia.

\section{DISCUSIÓN}

Predominio de tipos de hojas: En la Pluvisilva de baja altitud y submontana sobre ofiolitas y en la Pluvisilva submontana sobre suelos de mal drenaje el predominio de hojas micrófilas es una consecuencia directa de las características geológicas y edáficas donde estos bosques se desarrollan, principalmente por la presencia de la serpentina y por ende de los suelos derivados de este tipo de roca con un bajo tenor nutricional (Borhidi 1988), lo que propició la aparición de especies con hojas así durante los procesos de especiación. En todo ello también debió de haber influido la sequedad del clima, principalmente durante el Mioceno que fue árido (Samek 1973) y durante el Pleistoceno-Holoceno, donde ocurrieron cambios en el gradiente de temperatura (Ortega y Arcia 1982), lo que propició la reducción del limbo foliar.

El resultado obtenido está en correspondencia con lo encontrado por Borhidi (1991), al mencionar el fenómeno de la microfilia como uno de los rasgos más notables de la flora de Cuba. Ello también lo observaron Borhidi y Muñiz (1980), Fernández y Martínez (2000), Reyes y Acosta (2005 a), Franco et al. (2004), Vázquez (2004) y Ventosa (2004) en diferentes 
estudios y en muchas ocasiones lo relacionaron con el endemismo.

Por otra parte, la presencia mayoritaria de hojas mesófilas en la Pluvisilva de baja altitud sobre complejo metamórfico coincide con los resultados de Reyes y Acosta (2005 a) y se debe al gran desarrollo de la estera radical, embebida en una matriz de humus, que absorbe los nutrientes a partir de la descomposición de la horasca, ya que el suelo es ácido y muy pobre en nutrientes, por lo que sólo sirve como soporte mecánico. De manera que en este bosque las especies desarrollan hojas de mayor tamaño, como consecuencia de una mayor cantidad de nutrientes que provienen de su propio reciclaje y supera así los factores edáficos desfavorables (Fornaris et al., 2000).

Reyes (2006) encontró en la Pluvisilva montana una abundancia de hojas notófilas y macrófilas. Eso corresponde en parte con lo observado aquí, la diferencia radica en que las muestras de hojas procedentes de este bosque son en su mayoría micrófilas en este estudio; lo que pudiera estar relacionado con las características del edátopo, como la presencia de pendientes abruptas y pedregosidad en algunos casos, sin descartar el fenómeno de la oligotrofia (Renda et al. 1981). La existencia de pendientes de aquel tipo induce a un efecto de escorrentía, que a su vez provoca la lixiviación del suelo (Renda et al. 1981) y con ello el arrastre de los pocos nutrientes. Borhidi (1991) mencionó que la capa superior del estrato arbóreo en esta pluvisilva consiste de especies notófilas y micrófilas. Por otro lado, Reyes et al. (2005) señalaron las diferencias fisonómicas de las pluvisilvas montanas de la Gran Piedra y mencionaron que los bosques oligotónicos (con estrato arbóreo superior irregular) son generalmente mesófilos, mientras que los eutónicos (con estrato arbóreo superior continuo) son micrófilos, debido a la acción de los vientos Alisios que son la principal causa de tensión eólica de los últimos. De esta forma, el predominio de hojas micrófilas o mesófilas en este bosque va a estar en dependencia de la acción de determinados factores ecológicos.
Predominio de tipos de ápices: En este estudio se encontró un predominio de hojas con ápices acuminados en la Pluvisilva de baja altitud sobre complejo metamórfico y en la Pluvisilva montana lo que contribuye a eliminar el exceso de agua, mediante su escurrimiento, en hábitats con un alto régimen de precipitaciones. Eso a su vez es una ventaja adaptativa para bosques húmedos como estos, que otros autores observaron (Jungner 1891, Richards 1966, 1996, Dean y Smith 1978, Roth 1984, citados por Farji-Brener et al. 2002). La estrechez del acumen parece tener cierta importancia en la caída del agua debajo de la planta, de esta forma un ápice apiculado ofrece una mayor ventaja pues el goteo sería más lento y la erosión del suelo, menor (Willianson 1981, Willianson et al. 1983), pero sólo dos especies $(10 \%)$ de las estudiadas en la Pluvisilva montana presentan esta característica.

En las pluvisilvas que se desarrollan sobre complejo ofiolítico abundaron las hojas con ápices redondeados. Ello podría justificarse porque en general las especies con esas características forman parte del dosel u ocupan posiciones intermedias en la estratificación vertical del bosque, por lo que el desarrollo del acumen foliar es innecesario, ya que en los bosques tropicales húmedos la humedad relativa decrece desde el nivel del suelo hasta el dosel y el potencial de evaporación es más grande arriba que cerca de la superficie del suelo (Willianson 1981, Farji-Brener et al. 2002). Farji-Brener et al. (2002) demostraron que la presencia del acumen es más importante en los estratos bajos que en los altos y que en determinadas plantas arbóreas del dosel éste disminuyó en importancia relativa a medida que se convertían en individuos adultos. No obstante, las muestras de hojas analizadas aunque corresponden a especies que forman parte de los estratos superiores, se tomaron próximas a la superficie del suelo, pero ya maduras. Así que no se pudo constatar si durante los primeros estadios del desarrollo de las plántulas de estas especies aparecía el ápice gotero y por lo tanto corroborar si había influencia de algún factor ecológico, o simplemente si es un hecho que tiene que ver con las características taxonómicas de las mismas. 
Relación entre la estructura interna de las hojas con los factores abióticos: En la Pluvisilva de baja altitud sobre complejo metamórfico los patrones de las paredes anticlinales corresponden en su mayoría a hojas que se desarrollan en ambientes soleados, de acuerdo con lo expuesto por Wilkinson (1979). Según Reyes y Acosta (2005 a) este bosque se halla en una zona de alta pluviosidad, con un estrato arbóreo superior que puede llegar a alcanzar los $45 \mathrm{~m}$ de altura. A ello también se puede agregar que el dosel impide el paso de la luz directa la mayor parte de las veces. Por otra parte, Wilkinson (1979) señaló que en los trópicos el porcentaje de especies con paredes onduladas es mayor cuando decrece la altitud y de acuerdo con Reyes y Acosta (2005 a) esta pluvisilva no se encuentra por encima de los $400 \mathrm{~m}$ snm, razón por la cual las hojas de las especies que lo integran deberían de tener la epidermis con células de paredes onduladas, o al menos existir un predominio de éstas. Sin embargo, cabe la posibilidad de que este carácter esté fijado genéticamente y como tal sea expresado, independientemente de la interacción con los factores abióticos. Según Pyykkö (1966), la morfología externa e interna de las plantas se basa primariamente en el genotipo de las especies antes que en una adaptación a las condiciones que prevalecen en el medio.

Las características observadas en las paredes anticlinales de las especies de la Pluvisilva montana y las que se desarrollan sobre complejo ofiolítico se corresponden con lo planteado por Wilkinson (1979) y Ventosa (2004) en el sentido de la relación estructura interna-hábitat; así como también corroboran lo observado por Fontenelle et al. (1994) y Acosta y Vilela (1998) en cuanto a la presencia de caracteres mesomórficos y xeromórficos en especies de un mismo hábitat.

Respecto a los efectos causados por las estriaciones de la cutícula, Roth (1990) planteó que cuando existen en las células epidérmicas de la superficie adaxial pueden interferir en la absorción de la luz por los cloroplastos, además de dificultar el escurrimiento del agua en ambientes húmedos. Parece que el desarrollo de las estrías en la cutícula de las células epidérmicas, en esa superficie, en unas pocas especies de los bosques estudiados es un mecanismo efectivo que se manifiesta en condiciones umbrófilas y el alto grado de humedad que existe en ellos, fundamentalmente en la Pluvisilva de baja altitud sobre complejo metamórfico y en la Pluvisilva montana.

Según Puentes (2001) las pluvisilvas de la Subregión Grupo Orográfico de SaguaBaracoa están ubicadas en una zona de clima húmedo de vegetación de bosques y clima muy húmedo de bosques siempre húmedos. Por otra parte, Montenegro (1990) señaló que la Subregión Sierra Maestra presenta valores elevados de humedad relativa durante todo el año, de más del $87 \%$ hasta cerca del $92 \%$ entre los diferentes meses. Estas condiciones de alta humedad podría ser la causa directa de que una buena parte de las especies presentaran estomas gigantes sobre las venas de las hojas o próximos a éstas, porque ellos intervienen conjuntamente con otras estructuras epidérmicas en la secreción pasiva del exceso de agua, incluso Wilkinson (1979) y Roth (1990) afirmaron que pueden llegar a funcionar como hidátodos. Estos estomas, así como también las lenticelas y fisuras compensarían la carencia de hojas anfistomáticas, ya que la presencia de las células estomáticas en ambas superficies contribuiría a eliminar el exceso de vapor de agua. En otro sentido, el hundimiento de los estomas en criptas estomáticas y su recubrimiento por numerosos tricomas es un indicador de las condiciones xeromórficas, como señalaron Denffer (1974), Esau (1977), Wilkinson (1979), Roth (1990) y Ventosa (2004).

Según Roth (1990) la presencia de estriaciones cuticulares en las células anexas estomáticas, así como también en las oclusivas de algunas especies, constituye una ventaja adaptativa a las condiciones de alta humedad, ya que las esculturaciones de este tipo ayudan a retener el aire en las depresiones que se crean entre las protuberancias formadas por éstas, especialmente por encima de los estomas, reduciendo así el humedecimiento en una atmósfera casi saturada de vapor. Además, las estriaciones 
dispuestas de manera radiada pueden causar la salida del agua más rápidamente (evaporación cuticular) de manera que el intercambio gaseoso no estaría perturbado en un ambiente como este, de aquí se deduce la importancia de estas estructuras en las pluvisilvas, cuando se presentan en la superficie abaxial.

Respecto a la mayor o menor presencia de los tricomas en la superficie foliar, Esau (1977) se refirió a que éstos son abundantes en los xerófitos y Pyykkö (1966) y Alvin (1987) notaron que una superficie cubierta de tricomas es mucho más común en especies de hábitos secos y soleados que en aquellos de sombra y humedad; o como indicó Johnson (1968, citado por Johnson, 1975), que la pubescencia es más densa en las hojas maduras de los ambientes más secos. No obstante, Denffer (1974) y Johnson (1975) expusieron que las plantas de ambientes húmedos pueden presentar numerosos tricomas vivos en la epidermis para aumentar la superficie de transpiración. En este último sentido, se justifica la mayor presencia de los tricomas en las especies de la Pluvisilva montana. Por otro lado, su abundancia en la superficie abaxial de Miconia mirabilis y Ocotea cuneata al punto de llegar a cubrir los estomas podría tener un efecto similar al de las papilas, como indicó Wilkinson (1979), al facilitar el escurrimiento del agua de la superficie de las hojas, donde las precipitaciones son particularmente abundantes.

La presencia de las papilas en la epidermis de las hojas analizadas en este estudio se considera un fenómeno raro. Roth (1990) indicó que aumentan la evaporación cuticular, ya que poseen una cutícula muy fina y eso sería una gran ventaja en los hábitats húmedos, donde se hallan las dos especies que la presentan.

Roth (1990) expuso que las lenticelas y las fisuras intervienen en el intercambio gaseoso y además es probable que el agua sea secretada mediante estos orificios epidérmicos en forma de gotas líquidas, cuando la atmósfera está muy saturada de vapor, lo que justificaría el hecho de su aparición frecuente entre las muestras analizadas, sobre las venas o en las proximidades de éstas.
En general existe un predominio de la hoja micrófila, sobre todo en los endemismos de la Pluvisilva de baja altitud y submontana sobre ofiolitas, la Pluvisilva submontana sobre suelos de mal drenaje y la Pluvisilva montana, mientras que la Pluvisilva de baja altitud sobre complejo metamórfico es mesófila.

En las pluvisilvas sobre complejo ofiolítico abundan las hojas con el ápice redondeado, mientras que en la Pluvisilva de baja altitud sobre complejo metamórfico y en la Pluvisilva montana predominan las de ápice acuminado.

En la epidermis foliar la mayoría de las estructuras observadas son características de ambientes mesomórficos, pero algunas corresponden a los xeromórficos. Otras como las lenticelas, las fisuras y los estomas gigantes reflejan la adaptación a las condiciones de alta humedad atmosférica, por lo que se consideran higromórficas.

\section{AGRADECIMIENTOS}

A Silvia Donatién y Angela Beyra, por su valiosa ayuda en conseguir reactivos químicos y materiales necesarios para llevar a cabo el estudio epidérmico-foliar. A Hildelisa Saralegui, María M. León y José M. Plasencia, por las valiosas sugerencias y comentarios críticos realizados a este trabajo. A María E. Li por su colaboración en la digitalización del mapa.

\section{RESUMEN}

Se estudió la morfología foliar de los antófitos que son representativos de cuatro tipos de pluvisilvas de la Región Oriental de Cuba y se relacionó con los principales factores abióticos. Se encontró que existen varios tipos de hojas, pero predominó la micrófila en las especies endémicas y la mesófila, en las no endémicas. En la epidermis foliar se hallaron estructuras que son características de plantas mesomórficas y algunas xeromórficas, pero también se observaron otras que permiten una adaptación a las condiciones de alta humedad atmosférica, las que se consideraron higromórficas.

Palabras clave: morfología foliar, epidermis, pluvisilvas, ecología, Región Oriental de Cuba. 


\section{REFERENCIAS}

Acosta Castellanos, S. \& A. E. Vilela. 1998. Anatomía foliar y morfología del polen de Drymis granadensis var. mexicana (Winteraceae: Magnoliales). Polibotánica 8: 1-12.

Alvin, K. L. 1987. Leaf anatomy of Androstachys johnsonii Prain and its functional significance. Annals of Botany 59: 579-591.

Barthlott, W. 1981. Epidermal and seed surface characters of plants: Systematic applicability and some evolutionary aspects. Nordic J. Bot 1: 345-354.

Borhidi, A. 1976. Fundamentos de Geobotánica en Cuba. Tesis para el grado de Doctor en Ciencias Biológicas. Instituto de Botánica Vacratov, Academia de Ciencias de Hungría, Budapest, Hungría.

Borhidi, A. 1988. El efecto de la roca serpentina a la flora y vegetación de Cuba. Acta Bot Hung 34: 123-174.

Borhidi, A. 1991. Phytogeography and Vegetation Ecology of Cuba. Akadémiai Kiadó, Budapest, Hungría.

Borhidi, A. 1995. Es la flora de las Antillas de origen andino? Acta Bot Hung 39: 201-216.

Borhidi, A. \& O. Muñiz 1980. Die Vegetationskarte von Kuba. Acta Bot Hung 26: 25-53.

Cañas Abril, P. 1978. Principales regiones físico-geográficas. 1: 3000 000. p. 44-45. In Atlas de Cuba. XX Aniversario del Triunfo de la Revolución Cubana. Instituto Cubano de Geodesia y Cartografía, La Habana, Cuba.

Denffer. D. V. 1974. Morfología, p. 166-169. In E. Strasburger, F. Noll, H. Schenck \& A. F. Wilhelm Schimper (eds.). Tratado de Botánica. Marín, S.A. Barcelona, España.

Díaz Dumas, M. A. \& R. Rankin Rodríguez. 1998. Modificaciones anatómicas en plantas que crecen sobre suelos de serpentina. Rev. Jard. Bot. Nac. Univ. Habana 19: 61-65.

Esau, K. 1977. Anatomy of seed plants (2n. ed.). John Wiley \& Sons. Londres, Inglaterra.

Farji-Brener, A., O. Valverde, L. Paolini, M. A., La Torre, E. Quintero, E. Bonaccorso, L. Arnedo \& R. Villalobos. 2002. Función del acumen en las hojas y su distribución vertical en un bosque lluvioso tropical de Costa Rica. Rev. Biol. Trop. 50: 561-567.

Fernández Zequeira, M. D. \& M. C. Martínez Martínez. 2000. La microfilia en las Rubiáceas cubanas. Acta Bot Cub 143-149: 25-28.
Fontenelle, G. B., C. G. Costa \& R. D. Machado. 1994. Foliar anatomy and micromorphology of eleven species of Eugenia L. (Myrtaceae). Bot. J. Linn Soc.115: 111-133.

Fornaris, E., E. O. J. Reyes \& F. Acosta 2000. Características fisionómicas y funcionales de la Pluvisilva de baja altitud sobre complejo metamórfico de la zona nororiental de Cuba. Biodiversidad Cuba Oriental 4: 44-51.

Franco Flores, F., I. Castañeda Noa \& R. Oviedo Prieto. 2004. Flora ultramáfica de Motembo, Villa Clara, Cuba, p. 65-71. In R. S. Boyd, A. J. M. Baker \& J. Proctor (eds.). Rocas ultramáficas: sus suelos, vegetación y fauna, Science Reviews, Londres, Inglaterra.

Gutiérrez, J. E. 1991. Anatomía foliar de las especies cubanas de Casearia Jacq. Revista Jard Bot Nac Univ Habana 12: 45-67.

Johnson, H. B. 1975. Plant pubescence: an ecological perspective. Botanical Review 41: 233-258.

León Rodríguez M. M. \& A. López Almirall. 2005. Morfología de la flora endémica distrital de Sierra de Nipe, Holguín, Cuba. Acta Bot. Cub. 190: 26-27.

Martínez Quesada, E. 2006. Caracterización florística, morfológica y fitogeográfica de las pluvisilvas de la Región Oriental cubana, mediante espermatofitas. Tesis de maestría, Universidad de La Habana, La Habana, Cuba

Mateo Rodríguez, J. \& M. Acevedo González. 1989. Regionalización Físico-Geográfica 5. 1: 3000 000. In Nuevo Atlas Nacional de Cuba. La Habana.

Montenegro, U. 1990. Informe con los datos climáticos de la Gran Piedra. Academia de Ciencias de Cuba. Departamento de Meteorología de Santiago de Cuba, Santiago de Cuba, Cuba.

Núñez Jiménez, A. 1954. Geografía de Cuba. Lex, La Habana, La Habana, Cuba.

Núñez Jiménez, A. \& N. Viña Bayés. 1989. Regiones Naturales-Antrópicas 6. 1: 3000 000. In Nuevo Atlas Nacional de Cuba, La Habana.

Ortega, P. \& M. Arcia. 1982. Determinación de las lluvias en Cuba durante la glaciación de Wisconsin mediante relictos edáficos. Ciencias Tierra Espacio 4: 85-104.

Puentes, G. 2001. Regionalización climática de los macizos montañosos orientales, p. 14-25. In N. Viña-Bayés, A. Fong. \& D. Maceira. (eds.). Diversidad Biológica de los Macizos Montañosos de Cuba Oriental. Tomo I. Centro Oriental de Ecosistemas y Biodiversidad 
(BIOECO), Santiago de Cuba, Santiago de Cuba, Cuba.

Pyykkö, M. 1966. The leaf anatomy of East Patagonian xeromorphic plants. An. Bot. Fennici 3: 453-622.

Renda, A., E. Calzadilla, J. A. Bouza \& M. Valle. 1981. Estudio sobre las condiciones edafológicas, fisiográficas y agrisilviculturales de la Sierra Maestra. Centro de Investigaciones Forestales. Ministerio de la Agricultura, La Habana, La Habana, Cuba..

Reyes, O. J. \& F. Acosta Cantillo. 2005 a. Cuba: Parque Nacional "Alejandro de Humboldt" (Vegetación), p. 370. In A. Fong, D. Maceira, W. S. Alverson \& T. Wachter (eds.). Rapid Biological Inventories, Report 14. The Field Museum, Chicago, EEUU.

Reyes, O. J. \& F. Acosta. 2005 b. Cuba: Parque Nacional La Bayamesa (Vegetación), p. 243. In D. Maceira, A. Fong, W. S. Alverson \& T. Wachter (eds.). Rapid Biological Inventories, Report 13. The Field Museum, Chicago, EEUU.

Reyes, O. J., O. Pelicié, C. Vinent, L. M. Labrada, E. Semanat \& E. Fornaris. 2005. Estudio fisionómico y funcional de las pluvisilvas montanas de la Gran Piedra, Cuba. Foresta Veracruzana 7: 7-14.

Reyes, O. J. 2006. Clasificación de la vegetación de la Sierra Maestra. Biodiversidad Cuba Oriental 8: 28-42. .

Roth, I. 1990. Peculiar surface structures of tropical leaves for gas exchange, guttation, and light capture (Fissures in the epidermis, lenticels, giant stomata, glands, ocelli, papillas, and surface sculpturing), p. 185-238. In B. Rollet, Ch. Högermann \& I. Roth (eds.). Stratification of Tropical Forest as seen in Leaf Structure (Part 2). Kluwer Academic, Amsterdam, Holanda.

Samek, V. 1973. Regiones fitogeográficas de Cuba. Academia de Ciencias de Cuba. Serie Forestal 15: $1-60$.

Vázquez Ruiz,A. 2004. El género Croton L. (Euphorbiaceae) en las áreas ultramáficas cubanas, p. 43-45. In R. S. Boyd, A. J. M. Baker \& J. Proctor (eds.), Rocas ultramáficas: sus suelos, vegetación y fauna. Science Reviews. Londres, Inglaterra.

Ventosa Rodríguez, I. 2004. The genus Gochnatia Kunth from Cuban ultramafic areas, p. 47-53. In R. S. Boyd, A. J. M. Baker \& J. Proctor (eds.). Rocas ultramáficas: sus suelos, vegetación y fauna. Science Reviews. Londres, Inglaterra.

Viña Bayés, N. 2005. Cuba: Parque Nacional La Bayamesa (Características Físico-Geográficas), p. 243. In D. Maceira, A. Fong, W. S. Alverson, \& T. Wachter, (eds.). Rapid Biological Inventories, Report 13. The Field Museum, Chicago, EEUU.

Williamson, G. 1981. Driptips and splash erosion. Biotropica 13: 228-231.

Williamson, G., A. Romero, J. K. Armstrong, T. J. Gush, A. J. Hruska, P. E. Klass \& J. T. Thompson. 1983. Driptips, drop size and leaf drying. Biotropica 15: 232-234.

Wilkinson, H. 1979. The Plant Surface (Mainly leaf). Part. V. The Cuticle, p. 140-156. In C.R. Metcalfe \& L. Chalk (eds.). Anatomy of the Dicotyledons (2 nd edn). Vol. I. Clarendon, Oxford, Inglaterra. 